\title{
Construction of Basketball Short Video Bloggers Based on Fan Culture Research - An Example of Tiktok Video Team Wild Basketball Team
}

\author{
Chenshu Guo ${ }^{1, *}$ \\ College of Culture and Tourism, University of Jinan, Jinan, Shandong province, China, 250000 \\ *Corresponding author. Email: guo1246567128@163.com
}

\begin{abstract}
In recent years, with the all-round application of Internet technology and the trend of using fragmented time, the short video industry has developed rapidly with the help and support of capital. With the promotion of pop-up applications such as Tiktok, Kuaishou and WeSee and the boom of various industries entering the short video field, the industrialisation of basketball has developed rapidly and basketball-related videos have gained a lot of attention, giving rise to many basketball bloggers and generating clusters of millions of fans. Based on this, this paper adopts the literature method and questionnaire method, hoping to get the corresponding results by understanding literature on basketball fan culture, analyzing the explosive basketball bloggers and interpreting the data. After literature review and questionnaire analysis, this paper summarizes the remarkable characteristics of basketball fan culture in the short video era, including identity and cultural identity, entertainment empathy, learning drive, identity consumption, and idolize culture, and puts forward some relevant suggestions on the creation of basketball short video according to the basketball fan culture. It is evidently clear from the findings that a unique style and attention to high-quality content is better ways to adapt to the development of the short video era. In this way, sports short videos can gather a large number of fans' attention and develop better.
\end{abstract}

Keywords: Basketball, Short video, Media, Fans culture

\section{INTRODUCTION}

By March 2020, the number of short video users in China has reached 773 million, accounting for $85.6 \%$ of online video users, and the total time (quoted) for users to watch short videos every day has exceeded 300 million hours. [1]. With the rise of short video platforms, it has become the country's main leisure and entertainment channel second only to television.

As the world's leading short video platform, the Tiktok platform has a clear head start, with a huge user base, as well as an industrial leading position in terms of content richness and commercialisation exploration. According to Quest mobile data, in June 2020, the monthly active users of Tiktok reached 513.36 million, and the active user rate was $57.5 \%$. Similarly, basketball is the hottest and most popular sport in China. According to the 2018 China Basketball Industry White Paper released by Tencent Think Tank at the 2nd Digital
Sports Global Summit, among the two typical groups of young people under 20 and adults aged 25-35, the Internet users who gave the most feedback that their friends around them liked basketball were around 52\% and $40 \%$ respectively, ranking first among all sports. And there has been a transformative change in the way fans (especially young people) participate in sport. They are keen to watch sports videos in addition to going to workouts, but they are less likely to watch live sporting events, focusing more on areas such as content, using multiple devices to participate in events, and preferring highlights or key moments of games or matches [2]. An app like Tiktok, which concentrates on highlighting moments and entertaining basketball videos, is naturally a fertile ground.

When you open the Tiktok platform and search for basketball topics, there are nearly 200 billion plays on related topics alone. So many dramas naturally mean that there are a large number of basketball fans. They are a team of more than ten basketball bloggers with a 
total of 25.4 million followers, making them a very large IP video creation team in the field of basketball.

Based on the above background, this paper summarizes the performance of contemporary basketball fans, as well as their special spirit and behavior culture as fans from the perspective of short videos. Through the literature review and questionnaire survey, this paper finds out the short video creation mode suitable for basketball fans, and provides inspiration for basketball short video creation.

\section{LITERATURE REVIEW}

\subsection{Basketball fans culture}

The word "fans" was first formed around 1889 to refer to avid fans of popular culture and idolaters of popular culture. It is a contraction of the word fanatic, which was first used to describe avid boxing and baseball supporters. Fanatic was introduced to Britain in the mid-16th century, from the New Latin fanatics, which means insanely but divinely inspired.

At the age of mass cultural communication, fans culture is spreading across all spheres, previously in the world of entertainment and sports, but as fan culture has grown, it has even spread to the serious world of academia, education and politics, where figures with an authoritative image or who is loved and admired by the public have a large fan base. Fans often gather in organised and disciplined groups to find spiritual solace through a common emotional pursuit. Fans are a form of mass culture produced by the mass culture industry, a product of the culture industry and the mass media. The emergence of basketball fans in China was actually accompanied by the industrialisation and marketisation of basketball [3]. The emergence of the fan is essentially a cultural phenomenon, according to John Fisk: "Fandom is a universal feature of popular culture in industrial societies. Fans select certain performers, narratives or textual genres from mass-produced and mass-distributed entertainment lists (repertoire) and incorporate them into a self-selected category of popular culture. These performers, narratives or genres are then integrated into a highly pleasurable, highly referential popular culture" [3]. Basketball fans culture has also become an important part of popular culture and fans culture, and it plays an important role in the entertainment, interpretation and change of popular culture and the development of the basketball industry.

\subsection{Fans spirit culture}

Basketball fans culture, as part of popular culture, has the function of satisfying people's spiritual needs, and it has a very important spiritual role in the group, and basketball fans, as an identity of a social group, certainly reflects the meaning of this identity culture [4].
As a common symbolic identity among the group, basketball fans draw on the spiritual power of a team, a player or a basketball IP by believing in it, hoping to gain a group identity and thus gain recognition among the general public. They are connected by a common spiritual core and receive spiritual comfort they need through their actions. The late basketball star Kobe Bryant, for example, was most noted and admired for his Mamba spirit, which gave his fans the strength to never give up, to be brave, to work hard and to stay focused at all times. When sports fans follow, follow and support a particular idol, they also entertain themselves by doing so, gaining the benefits of relaxation, relief and upliftment.

\subsection{Fans behavior culture}

On a behavioral level, fans often learn the signature moves of their idols in their favourite field or seek to emulate them in order to gain their own psychological identity. While one of the most notable behaviors of basketball fans is playing the sport, they share a common passion and desire to get better at the sport to gain the satisfaction of progress and improve their status within the basketball fan base. This is the culture of fan learning. Furthermore, fan culture research is essentially a type of audience (consumer) research, and the core interest of fan culture research is to break away from simplistic and idiotic audience theory to explain the complexity of fan consumption behavior [5]. The consumer behavior of fans is to pursue a common symbolic identity. What fans are pursuing is not a common brand, function or model to meet their needs and enjoyment, but a common code and a symbol. On the other hand, fans' consumption behavior is characterised by blindness, madness and irrationality compared to ordinary consumers, who have a richer emotional connotation. In addition to learning and consumption, fan behavior also includes a special form of interaction with idols (meeting them in person), which can satisfy their sense of identity to the highest degree and give them spiritual satisfaction by meeting them in person or even interacting with them up close. Even if it is not possible to get up close and personal, the group activity of fans has a collective meaning in itself.

\section{METHODS}

In this study, questionnaire survey was used. The questionnaire was based on the basketball fan base that the author is part of and has common characteristics of basketball fans, based on their existing features, combined with their preferences for basketball videos in the short video era. The questionnaire was posted online and 60 questionnaires were distributed and returned, of which 60 were valid. 
The questionnaire consisted of 14 questions. The first three questions are about the basic information of the interviewee's age, sex and city of residence. Then, from the content preference and whether to consume

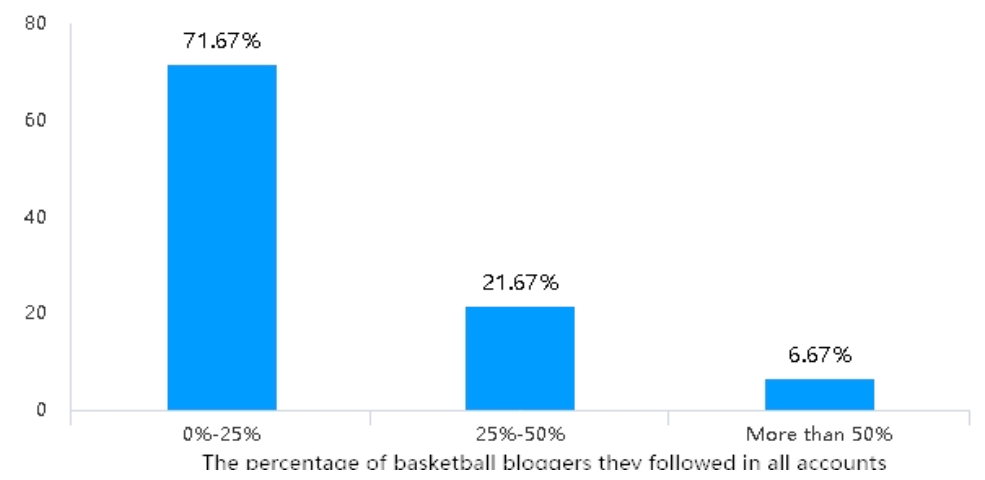

Figure 1 The percentage of basketball bloggers they follow in all accounts

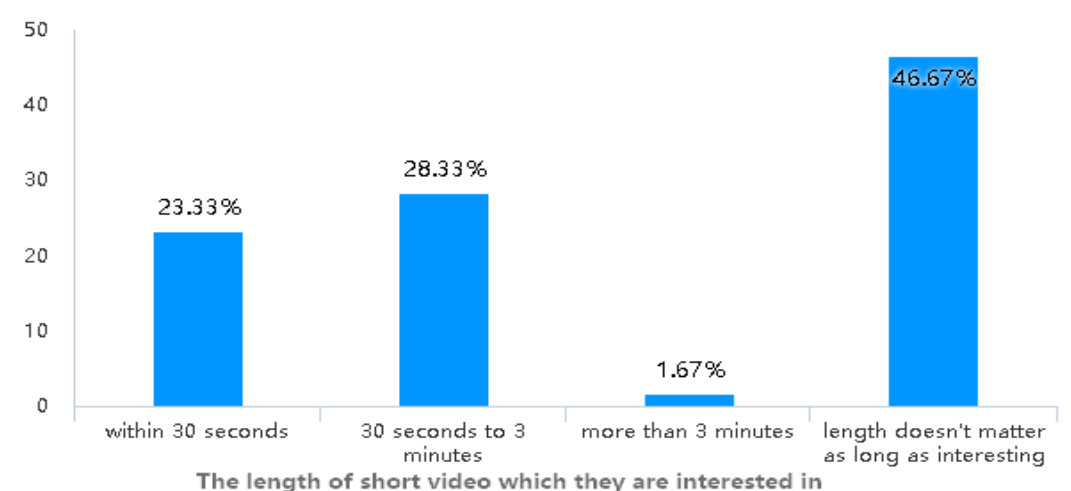

Figure 2 The length of short video which they are interested in basketball products, the respondents' preference for the content and consumption behavior of basketball short video was analyzed.
Figure 1 and Figure 2 reflect that among basketball fans, the vast majority of people follow a certain number of basketball bloggers on the Tiktok platform, with most of them following basketball bloggers at around 25\%, and that at the present time when fragmented reading is flourishing and the pace of life is accelerating, people tend to prefer short videos of 30 seconds to 3 minutes, but $46.67 \%$ of them think that length is not important as long as the content is interesting, indicating that in the short video era, capturing the interest of users is the key to winning.

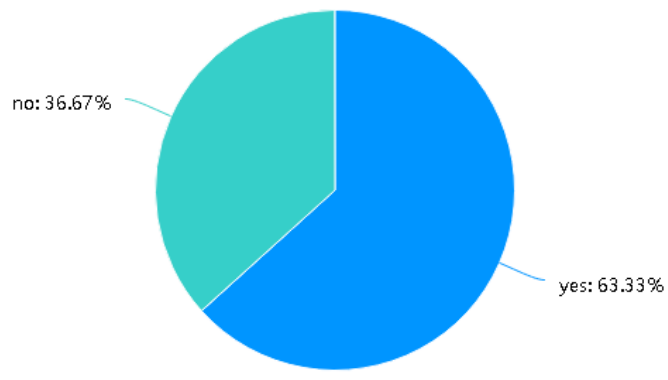

Figure 3 Have you ever watched the videos from "The king of street basketball" team? 


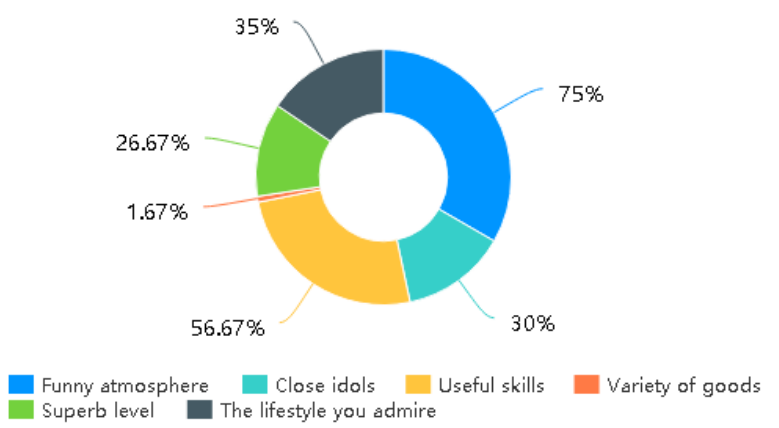

Figure 4 What elements attract you the most in the video of "The king of street basketball "team?

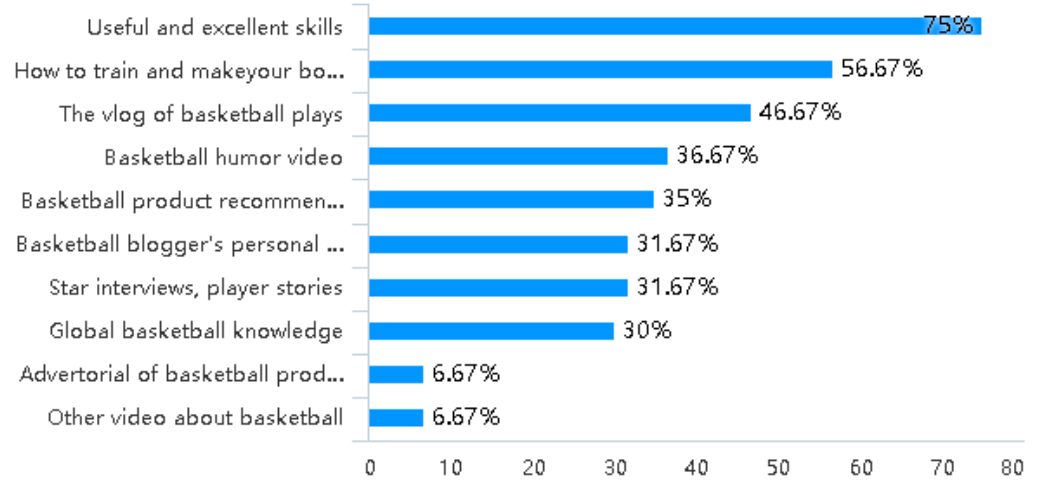

Figure 5 What other basketball content in short video you will like and follow?

Through the survey and Figure 3, more than sixty percent of basketball fans are fans of "The king of street basketball" or have at least watched short videos by the king of street basketball, indicating that the king of street basketball does have a high popularity and visibility among basketball fans who watch Tiktok. In addition, by analysing the video content of "The king of street basketball", we found that most of the content was sharing of basketball tips, sharing of life as a basketball blogger and highlights of the team bloggers playing together from Figure 4 and 5. To summarise the reasons for the popularity of the king of street basketball, we can see from the data that basketball fans prefer their funny style of video and the detailed and useful basketball tips in their videos. They also love to watch their videos because of their great skills, their close interaction with their fans and the life that most basketball fans envy in their videos.

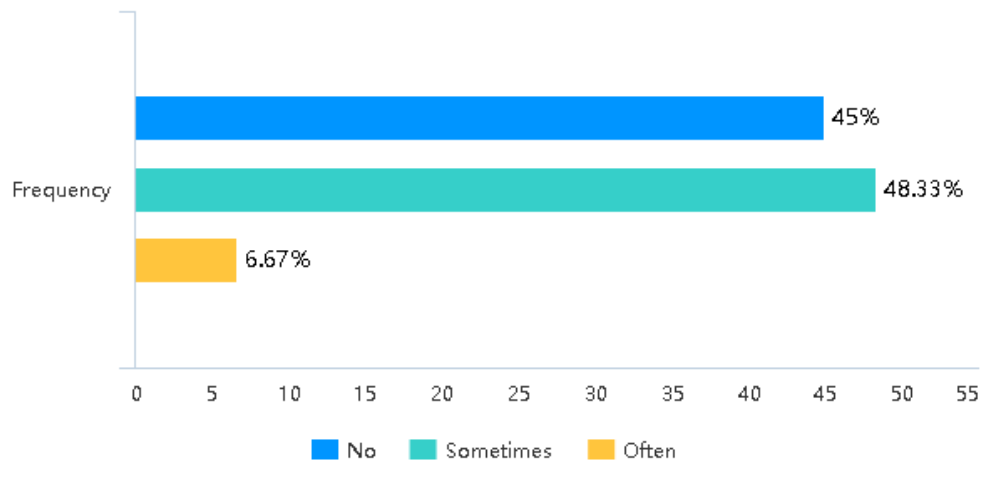

Figure 6 Will you watch basketball videos and buy related products? 


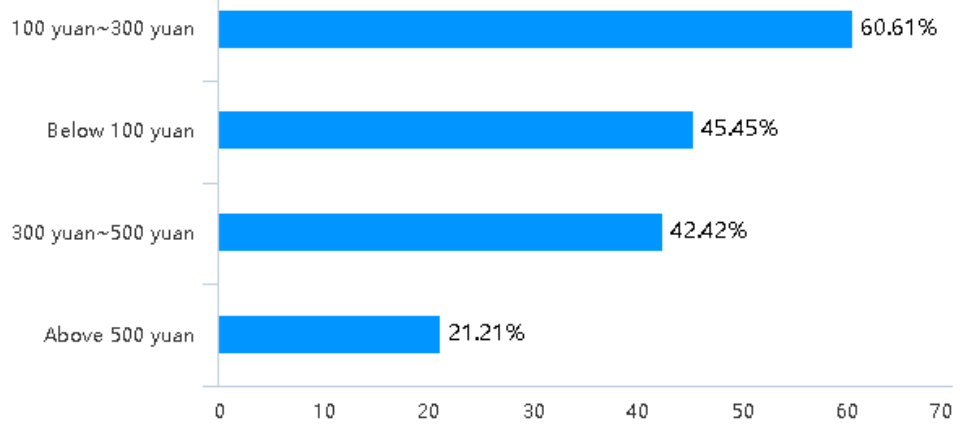

Figure 7 The prices range of basketball-oriented products you can accept are?

According to Figure 6 and 7, close to half of basketball fans will buy basketball products according to their needs, but the youth basketball group does not yet have a stable financial source, so products in the range of RMB 100-300 are their primary choice. The huge fan base of "The king of street basketball" has laid the foundation for basketball spending, and the stylish, functional and trendy basketball peripherals are also a necessity for most basketball fans. With the industrialisation of basketball and the prevalence of street culture, various styles of products linked to it will also be favoured by consumers.

\section{DISCUSSION}

Combined with the analysis of the characteristics of basketball fan culture, we can understand the preferences of basketball fans on today's short video platforms, which then has a very important guiding role in the account building and fan marketing of the same type of basketball bloggers.

Star is defined by Fisk in Key Concepts: A Dictionary of Communication and Cultural Studies: an individual who is famous for his or her public performances on screen and other media and is seen as an important symbol within and between various cultural groups [6]. Stars are famous because they rely on the role of mass media, and the medium for The king of street basketball Tee is the platform. In this paper, the distribution of short videos on the Tiktok platform is based on the "traffic pool" overlay recommendation algorithm, i.e. short videos that perform better in the traffic pool will enter the overlay recommendation ranks, thus gaining more plays and likes [7]. Most short video platforms have their own recommendation distribution models and special user profiling systems as a way of recommending videos of interest to users or recommending bloggers' videos to matching users. Basketball bloggers have to have an exclusive pool of traffic and a fixed target of recommendations. First of all, they have to define their own positioning and vertically segment into specific areas, then they will have the possibility to be loved by professional viewers. It is obviously a waste to recommend the videos of basketball creators to people who never exercises. Therefore, make your account positioned as a basketball blogger, rather than sports, football, fitness, etc. The more refined the better. Doing a good job of typecasting, positioning yourself distinctly and being recognized by the recommendation system will be the first step to become a well-known basketball blogger.

According to the previous study, videos in the basketball skills instruction category can gain the maximum interest from basketball fans. After getting targeted recommendations and huge traffic from the system, how to get the interest of the audience and get attention will be an important step. According to our summary of basketball fan culture, skills learning is the core purpose of following basketball bloggers, and it is with the admiration of high level basketball bloggers and the desire to improve their skills by following them that basketball fans start to follow them and become their fans step by step. This is why basketball bloggers need to keep their content at the core of their philosophy, strengthen their content creation and send high quality instructional videos to their fans in order to gain their attention.

Finally, developing a unique style is good for bloggers to strengthen the relationship with their fans. In the case of the the king of street basketball, for example, the humorous style of their videos is the most important factor for fans to like them. This humour brings them closer to their fans and is reinforced by posting videos that interact with them. Fans go for mental enjoyment and entertainment with a particular behavioral culture learning, consuming and following the stars - and this access is promoted to the extent that it is available to fans. The relationship between basketball fans and their idols is reinforced by the king of street basketball fans Festival, daily interactions and campus tours, which turn ordinary fans into "hardcore fans" and create a good organic interaction between bloggers and fans.

\section{CONCLUSION}

Through questionnaire analysis and reading related literature on fan culture research, in 
order to maximize the fan base and mutual intimacy of basketball bloggers in the short video era, it is necessary to keep a thorough study of the platform mechanism and gain insight into the emotional and behavioral needs of fans, which is the way to realize the construction of video account. At the same time, video makers should insist on content-oriented, content-above-all, and capturing the fans' love with high-quality content. Only in this way, producers of sports short videos can handle the keys to improve their influence on fans and enter the better group of them. Otherwise, this paper can give a lot help for those people who want to get better performance on video production.

\section{AUTHORS' CONTRIBUTIONS}

This paper is independently completed by Chenshu Guo.

\section{REFERENCES}

[1] XIE P P. Discussion on content innovation and value communication of cultural programs aimed at young audiences in the era of media convergence [J]. Journal of Chongqing University of Posts and Telecommunications(Social Science Edition), 2020 , 32(6): 157-164.

[2] Ennis S. Sports Marketing [M]. Palgrave Macmillan, Cham, 2020.

[3] John Fiskmei, Lu Daofu, Yang Lingxiao. The cultural economy of fans [J]. World Cinema, 2008, 000(006):165-179.

[4] Li Fengrong, Lei Zhen, Wang Lisen. Sports Fans and Contemporary Mass Sports Culture [J]. Journal of Chengdu Sport University, 2011, 37(005):59-62.

[5] Tao Dongfeng. Research on Fan Culture: Reading-New Development of Acceptance Theory [J]. Social Science Front, 2009 (07): 164-172.

[6] Fiske J. Key Concepts: Communication and Cultural Studies Dictionary [M]. 2. Xinhua Press, 2004.

[7] ZHAO C W, LIU T, DU H H. Research on video recommendation mode of Tiktok short video platform under algorithm view [J]. View on Publishing, 2019 (18): 76-78. 